\title{
A conceptual framework for climate change, health and wellbeing in NSW, Australia
}

\author{
Sinead Boylanª, Kathleen Beyer ${ }^{\mathrm{b}}$, David Schlosberg ${ }^{\mathrm{c}}$, Anastasia \\ Mortimer ${ }^{c}$, Neil Hime ${ }^{a, d}$, Benjamin Scalley ${ }^{d}$, Robyn Alders ${ }^{e}$, Carlos \\ Corvalan ${ }^{\mathrm{a}, \mathrm{d}, \mathrm{f}}$ and Anthony Capona,f
}

a School of Public Health, University of Sydney, NSW, Australia

${ }^{b}$ NSW Office of Environment and Heritage, Sydney, Australia

c Sydney Environment Institute, University of Sydney, NSW, Australia

d Environmental Health Branch, Health Protection NSW, NSW Health, Sydney, Australia

e School of Life and Environmental Sciences, University of Sydney, NSW, Australia

† Guest Editor, Public Health Research \& Practice, Issue 4, 2018

${ }^{g}$ Corresponding author: sinead.boylan@sydney.edu.au

\section{Article history}

Publication date: December 2018

Citation: Boylan S, Beyer K, Schlosberg D, Mortimer A, Hime N, Scalley B, Alders R, Corvalan C, Capon A. A conceptual framework for climate change, health and wellbeing in NSW, Australia. Public Health Res Pract. 2018;28(4):e2841826. https://doi. org/10.17061/phrp2841826

\section{Key points}

- Climate change may adversely affect health and wellbeing in New South Wales (NSW), Australia, and disproportionately impact socially, culturally and economically vulnerable groups and individuals

- A conceptual framework for the health and wellbeing impacts of climate change in NSW is proposed. The framework is intended to assist policy development and support the aims and objectives of the NSW Government's Climate Change Policy Framework, especially in relation to adaptation to climate change and reducing impacts on health and wellbeing

\section{Abstract}

Changes in natural hazards related to climate change are evident in New South Wales (NSW), Australia, and are projected to become more frequent and intense. The impacts of climate change may adversely affect health and wellbeing, directly via extreme weather events such as heatwaves, storms and floods, and indirectly via impacts on food security, air and water quality, and other environmental amenities. The NSW Government's Climate Change Policy Framework recognises the need to reduce the effects of climate change on health and wellbeing. A conceptual framework can support the aims and objectives of the policy framework by depicting the effects of climate change on health, and individual and social wellbeing, and areas for policy actions and responses. A proposed conceptual framework has been developed, modelled on the Driving force, Pressure, State, Exposure, Effect and Action (DPSEEA) framework of the World Health Organization - a framework which shows the link between exposures and health effects as well as entry points for interventions. The proposed framework presented in this paper was developed in consultation with researchers and policy makers. The framework is guiding current research examining vulnerabilities to climate change and the effects of a range of exposures on health and wellbeing. 


\section{Introduction}

\section{Climate change in NSW}

Like everywhere else on the globe, the climate of New South Wales (NSW), Australia, is changing. The temperature in NSW is projected to increase by $0.7^{\circ} \mathrm{C}$ in the near future (2020-2039) and $2.1^{\circ} \mathrm{C}$ further in the second half of this century (2060-2079). ${ }^{1}$ Although there will be regional differences in the extent of temperature change, all regions will become warmer. Rainfall is projected to increase moderately in northeastern NSW during summer and significantly decrease in southern and western NSW during winter and spring. ${ }^{1}$ Evaporation is also projected to increase across much of the state by 2050 due to the higher temperatures, leading to drier soil conditions in the west of the state. Increases in the frequency and intensity of some natural hazards, including heatwaves ${ }^{2}$, heavy precipitation ${ }^{3}$ and severe bushfire conditions ${ }^{4}$, are already being observed.

\section{The effects of climate change on health and wellbeing in NSW}

The impacts of climate change are far-reaching and go beyond changes to physical and ecosystem processes. Climate change has been described as the greatest public health threat of the 21 st century ${ }^{5}$, and a core task is the development of frameworks for public policy responses. Recently, the Framework for a National Strategy on Climate, Health and Well-being for Australia was released to support the Australian Government in protecting the health and wellbeing of communities from climate change. ${ }^{6}$

In general, climate change may affect health by changing the prevalence and distribution of existing environmental health effects. Extreme events in NSW such as heatwaves, droughts, bushfires, storms and flooding are already responsible for considerable disease, injury and mortality. These events have direct effects on health as well as indirect impacts on health and wellbeing through effects on food, water, air, livelihoods and people's homes. For example, bushfires directly result in injury and also aggravate lung and heart conditions via particle pollution associated with smoke, as well as having adverse consequences for mental health. ${ }^{7,8}$ Repeated exposure to extreme weather events also affects mental health and wellbeing due to reduced social cohesion, networks and support.9,10

In addition to impacts from individual extreme weather events, prolonged environmental consequences of climate change are likely to affect health and wellbeing. For example, climate change impacts on environmental nutrient cycling, via effects on soil carbon and plant growth, will potentially have flow-on effects for food production and food security. ${ }^{11}$

\section{NSW climate change policy}

Consistent with the level of effort to achieve Australia's commitments to the Paris Agreement, the NSW Climate Change Policy Framework was released in 2016, setting out roles, responsibilities and policy directions for the NSW Government. ${ }^{12}$ It describes the NSW Government's commitment to achieving net-zero emissions by 2050 and to making NSW more resilient to a changing climate. Specifically, in relation to impacts and adaptation, the NSW Government's operational role is to "assess and effectively manage climate change risk to government assets and services". Policy directions include to: 1) reduce risks and damage to public and private assets in NSW arising from climate change; 2) reduce climate change impacts on health and wellbeing; and 3) manage impacts on natural resources, ecosystems and communities.

One of the key challenges for NSW is to mitigate and adapt to more frequent and intense environmental hazards, and the impacts that a changed climate has on essential environmental amenities such as air and water. Climate adaptation and risk management relies on credible, robust and up-to-date information to support evidence based decision making. In 2017, the Human Health and Social Impacts Node ('the Node') was established - a collaborative research partnership between the University of Sydney, Edge Environment, the NSW Office of Environment and Heritage (OEH) and NSW Health. ${ }^{13}$ The Node will be informed by ecosocial understandings of the relationships between climate change, human health, individual and social wellbeing, and the environmental, social and economic consequences of climate change, as well as regional variation in impacts and vulnerability.

\section{The need for a conceptual framework for NSW}

A conceptual framework that depicts the impacts of climate change on health, and individual and social wellbeing, and areas for policy action and responses, is required to support the aims and objectives of the NSW Climate Change Policy Framework. The term 'conceptual framework' is used here to denote the representation of any concepts that can assist the design and development of policy actions aimed at reducing climate-sensitive health effects. ${ }^{14}$ One important use of the framework would be to distinguish essential (e.g. from a regulatory perspective) from desirable (e.g. for research interests) information for policy development. In addition, the framework illustrates the breadth of potential policy responses, and could be used to distinguish between policy responses that address mitigation, adaptation or responses to shock events.

Globally, the potential impacts of climate change on human populations vary widely and are likely to be 
far-reaching. However, as a consequence of the local physical environment, ecosystems, and social and health contexts in NSW, some climate change impacts, but not others, are particularly pertinent to health and wellbeing. Furthermore, NSW has a relatively high capacity (aided by the NSW Climate Change Policy Framework) to advance health and wellbeing in the face of a changing climate - capacity that is not afforded to low- and middleincome countries. Although it is important to develop a conceptual framework applicable to the opportunities and risks that climate change poses to health in NSW, we believe that this conceptual framework can serve as a model for other state or regional responses in Australia and beyond.

\section{Development of the conceptual framework}

Conceptual frameworks for climate change and health already exist and can be categorised into typologies of climate change assessments, guidelines for climate change risk assessment, conceptual frameworks for vulnerablity and adaptation to climate change, typologies of adaptation measures and adaptive systems, and evaluation frameworks for adaptive strategies. ${ }^{14}$ However, no single framework is suitable for all social, economic, environmental and policy environments.

The Driving force, Pressure, State, Exposure, Effect and Action (DPSEEA) framework of the World Health Organization is widely applied in environmental health. It is designed to support decision making about actions to reduce the burden of disease by describing environmental health problems from their root causes to their health effects, and by identifying areas for intervention. ${ }^{15}$ The framework was, for example, chosen to support the development of a core set of environmental health indicators in Australia. ${ }^{14}$ Because of its wide applicability to environmental health issues and its previous use in an Australian context, the DPSEEA framework was chosen as the basis for the development of the proposed conceptual framework for the Node. The framework was further developed following a 1-day workshop and ongoing consultation with stakeholders, researchers and decision makers.

Figure 1 presents the proposed conceptual framework. This framework aims to differentiate between the driving forces, pressures and state of the environment, and the health and social impacts, to illustrate where different policy actions and responses can address varying stages of impacts.

\section{Implementation of the framework}

Research projects under the Node are currently examining the effects of a range of exposures on health and wellbeing and the interplay with vulnerability. ${ }^{13}$ These projects include a scoping study on the intersections between vulnerability, housing tenure and adaptation responses to extreme heat; building climate resilience through policy-engaged mental health research; assessing novel surveillance technologies to detect exotic mosquitoes in northern NSW; and vulnerability and adaptation regarding climate change and allergy. The framework and research projects may lead to policies that address housing design to minimise heat exposure, social resilience strategies, mosquito monitoring and the impacts of aeroallergens.

The next step is for the framework to undergo a series of in-depth consultations with policy makers across a range of sectors in NSW. Effective adaptation and event response policies are crucial for minimising the health and wellbeing impacts of climate change. It is acknowledged that many of the driving forces and pressures presented by this framework are outside the jurisdiction of the NSW Government. However, the framework highlights that developing mitigation policies (e.g. for energy efficiency, transport, etc.) to support the NSW Climate Change Policy Framework is within its remit.

The NSW Government is actively assessing regional vulnerabilities and working to improve government service planning and delivery to build community climate change resilience. Although this framework has been developed for the state of NSW, it could be applied more widely to complement national efforts, given Australia's commitment to reduce emissions by $2030 .{ }^{16}$ It may also be tailored for other countries, as it highlights the wide range of health impacts from climate change and where mitigation and adaptation policies may be implemented.

\section{Benefits of the framework}

\section{Co-benefits of climate change adaptation policies}

One of the key ways in which the framework can lead to action is by illustrating effective and efficient policy pathways. Specifically, climate change adaptation policies that have co-benefits for health are to be encouraged. ${ }^{17}$ For example, the NSW OEH guidelines to support urban green cover may have not only environmental benefits such as improving air quality and filtering waste water, but also more direct health benefits (e.g. by reducing exposure to urban heat, lowering stress and behavioural disorders, increasing physical activity and creating community cohesion). ${ }^{18}$ This initiative is important given that almost $90 \%$ of the NSW population live in urban environments. ${ }^{18}$ The structure of the framework enables the multiple benefits of policies to be understood - leading to more likely policy adoption. 
Figure 1. Proposed conceptual framework for climate change impacts on human health and wellbeing in NSW

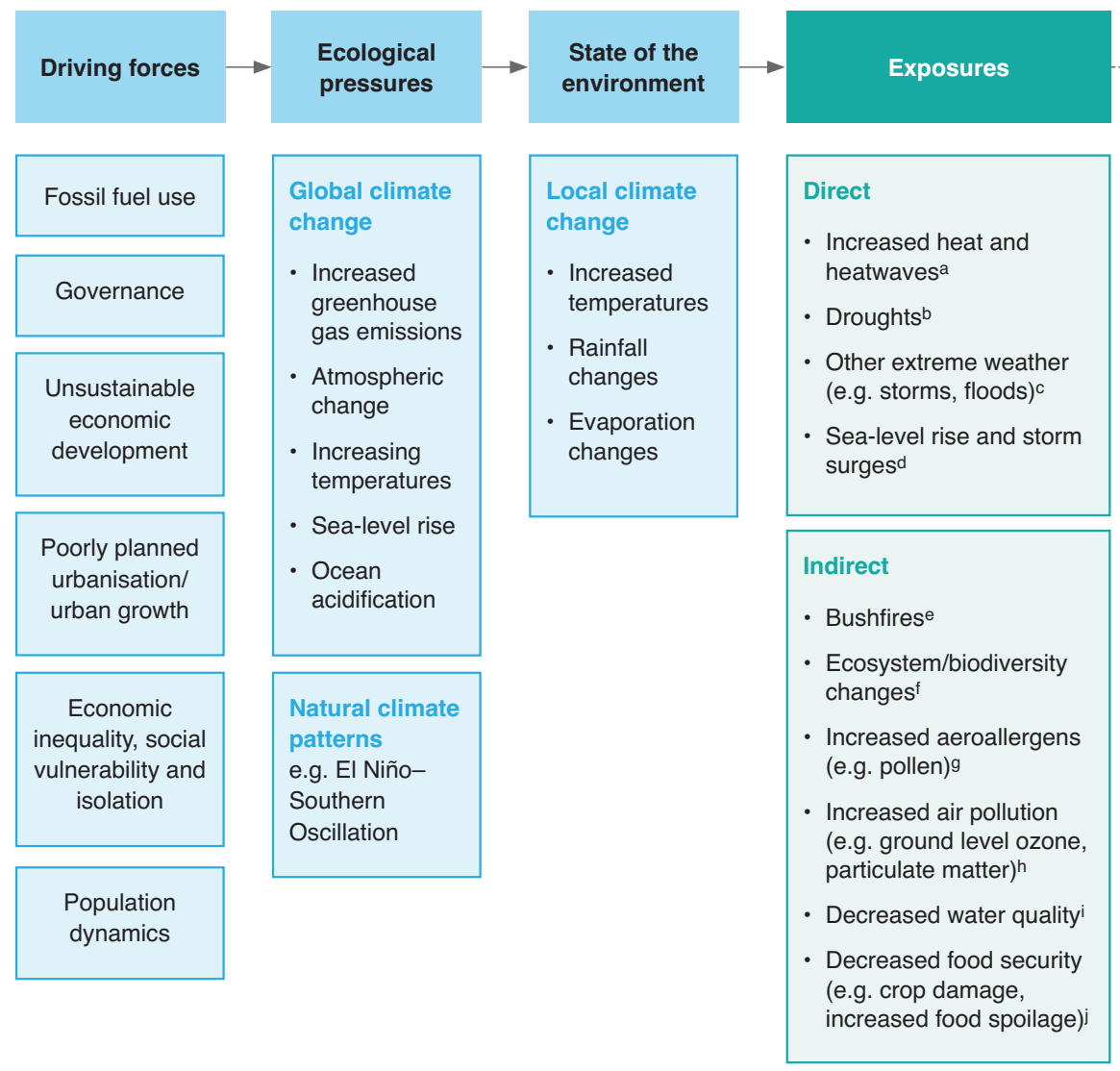

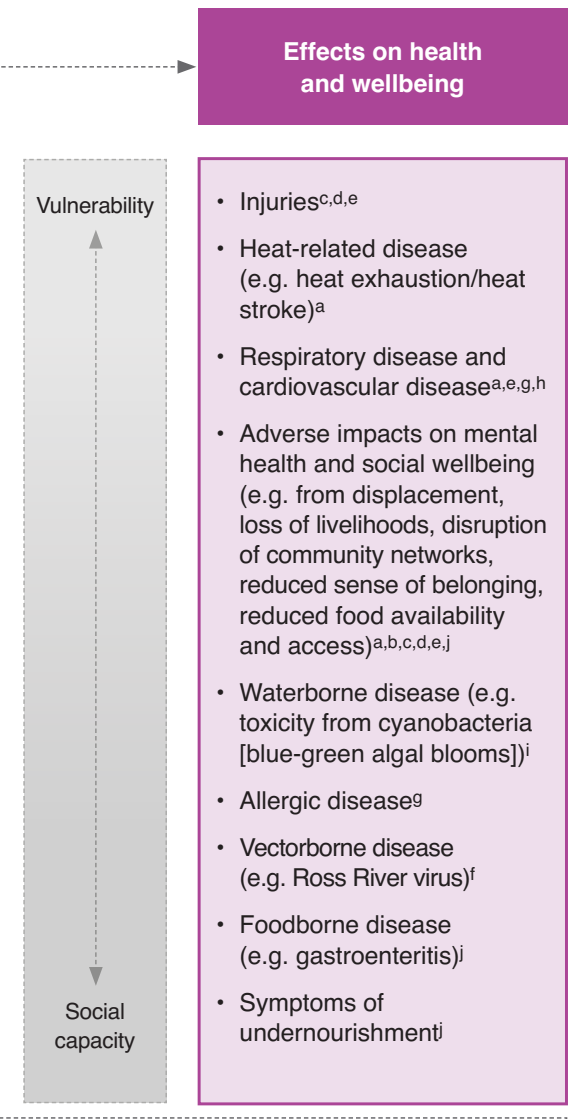

Consequences and co-benefits
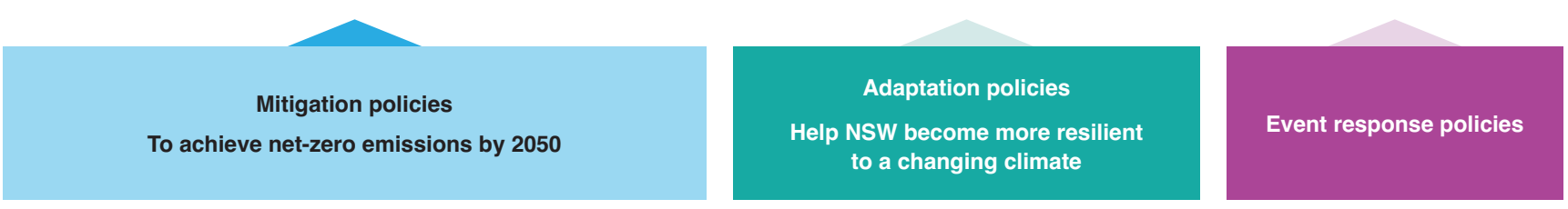

\section{Actions}

Note: Superscript letters denote relationships between specific exposures and effects on health and wellbeing

\section{Consideration of vulnerability, social cohesion and support}

One central issue in this framework is differential vulnerability to climate change risks. Climate change will disproportionately affect socially, culturally and economically vulnerable groups and individuals who may lack the basic capabilities, social networks and resources to respond to exposures and shock events. ${ }^{19}$ The framework identifies that vulnerability is a mediating factor between exposure and effect, and a threat multiplier - it is, for example, a key concept that helps to differentiate between broad exposures and risks, and more specific vulnerabilities and impacts. In addition to the usual socio-economic indicators, vulnerabilities include housing quality, ability to travel/retreat and social networks.
Strong social cohesion and support networks between individuals, communities and institutions are essential for building the adaptive capacity of vulnerable populations. ${ }^{9}$ Studies on adaptive capacity, vulnerability and climate change have shown how a focus on capabilities and social cohesion in adaptation policy can strengthen support networks, adaptive capacity and wellbeing on individual, community and institutional levels. ${ }^{20}$ Residents without such support systems tend to be more vulnerable to climate risks, such as heatwaves. 


\section{Conclusion}

As the climate of NSW continues to change, it is important that we progress our understanding to identify and respond to the effects of climate exposures on health and wellbeing, and continue to develop and implement effective and efficient cross-sectoral adaptation and response policies. It is hoped that the proposed framework supports a clearer understanding of these impacts on health, wellbeing, and individual and social vulnerability, and highlights where adaptation and response policies may best be implemented in NSW. It is also hoped that the framework could be tailored for other regions and states of Australia and beyond.

\section{Acknowledgements}

This research has been funded by the NSW Office of Environment and Heritage and is supported by NSW Health. We thank the researchers and decision makers who attended a 1-day workshop and provided input into the development of the proposed framework.

\section{Peer review and provenance}

Externally peer reviewed, commissioned.

\section{Competing interests}

AC directs the Human Health and Social Impacts Node hosted by the University of Sydney with financial support from the NSW Office of Environment and Heritage and NSW Ministry of Health.

\section{Author contributions}

SB led the writing of this manuscript. All other authors commented on various drafts of the framework and manuscript and have read and approved the final manuscript.

\section{References}

1. Olson R, Evans JP, Di Luca A, Argüeso D. The NARCliM project: model agreement and significance of climate projections. Climate Research. 2016;69:209-27.

2. Perkins-Kirkpatrick SE, White CJ, Alexander LV, Argueso D, Boschat G, Cowan T, et al. Natural hazards in Australia: heatwaves. Climatic Change. 2016;139(1):10114.

3. Alexander LV, Hope P, Collins D, Trewin B, Lynch A, Nicholls N. Trends in Australia's climate means and extremes: a global context. Australian Meteorological Magazine. 2007;56:1-18.
4. Clarke H, Lucas $\mathrm{C}$, Smith $\mathrm{P}$. Changes in Australian fire weather between 1973 and 2010. Int J Climatol. 2013;33:931-44.

5. Costello A, Abbas M, Allen A, Ball S, Bell S, Bellamy R, et al. Managing the health effects of climate change. Lancet. 2009;373(9676):1693-733.

6. Horsburgh N, Armstrong F, Mulvenna V. Framework for a national strategy on climate, health and well-being for Australia. Melbourne: Climate and Health Alliance; 2017 [cited 2018 Mar 21]. Available from: d3n8a8pro7vhmx. cloudfront.net/caha/pages/40/attachments/ original/1498008324/CAHA_Framework_for_a_National_ Strategy_on_Climate_Health_and_Well-being_v05_ SCREEN_\%28Full_Report\%29.pdf?1498008324

7. NSW Environmental Protection Authority. Sydney: NSW EPA; 2015. Air quality: state of the environment; Nov 2017 [cited 2018 Mar 19]; [about 10 screens]. Available from: www.epa.nsw.gov.au/about-us/publications-and-reports/ state-of-the-environment/state-of-the-environment2015/08-air-quality

8. Gibbs L, Bryant R, Harms L, Forbes D, Block K, Gallagher $\mathrm{HC}$, et al. Beyond bushfires: community resilience and recovery final report. Melbourne: University of Melbourne; 2016 [cited 2018 Mar 19]. Available from: beyondbushfires.org.au/_data/assets/pdf_ file/0003/2183511/Web_Beyond-Bushfires-Final-Report2016-copy.pdf

9. Klinenberg E. Heat wave: a social autopsy of disaster in Chicago. Chicago: The Chicago University Press; 2002.

10. Rigby CW, Rosen A, Berry HL, Hart CR. If the land's sick, we're sick: the impact of prolonged drought on the social and emotional well-being of Aboriginal communities in rural New South Wales. Aust J Rural Health. 2011;19(5):249-54.

11. Department of Environment Climate Change and Water NSW. NSW climate impact profile: the impacts of climate change on the biophysical environment of New South Wales. Sydney: Department of Environment, Climate Change and Water NSW; 2010 [cited 2018 Mar 19]. Available from: www.climatechange.environment.nsw. gov.au/Impacts-of-climate-change/2010-NSW-climateimpact-reporting

12. Office of Environment and Heritage. NSW Climate Change Policy Framework. Sydney: State of NSW and Office of Environment and Heritage; 2016 [cited 2018 Mar 19]. Available from: www.environment.nsw.gov.au/-/ media/OEH/Corporate-Site/Documents/Climate-change/ nsw-climate-change-policy-framework-160618.pdf

13. The University of Sydney. Sydney: University of Sydney; 2017. Climate Change, Human Health and Social Impacts Research Node; 2018 [cited 2018 Mar 19]; [about 3 screens]. Available from: sydney.edu.au/medicine/ public-health/research/hhsi-node.php 
14. Füssel HM, Klein RJT. Conceptual frameworks of adaptation to climate change and their applicability to human health. Postdam, Germany: Potsdam Institute for Climate Impact Research (PIK); 2004 [cited 2018 Mar 19]. Available from: www.pik-potsdam.de/research/ publications/pikreports/.files/pr91.pdf

15. Corvalán C, Kjellström T, Smith K. Health, environment and sustainable development: identifying links and indicators to promote action. Epidemiology. 1999;10(5):656-60.

16. Australian Government. Australia's 2030 climate change target. Canberra: Australian Government; 2015. [cited 2018 Jul 31]. Available from: www.environment.gov. au/system/files/resources/c42c11a8-4df7-4d4f-bf924f14735c9baa/files/factsheet-australias-2030-climatechange-target.pdf

17. Haines A, Wilkinson P, Tonne C, Roberts I. Aligning climate change and public health policies. Lancet. 2009;374(9707):2035-8.
18. NSW Government: Environment \& Heritage. Sydney: State of New South Wales and Office of Environment and Heritage. Urban green cover in NSW: technical guidelines [cited 2018 Mar 19]; [about 3 screens]. Available from: www.climatechange.environment.nsw. gov.au/Adapting-to-climate-change/Green-Cover

19. Lindley S, O'Neill J, Kandeh J, Lawson N, Christian R, O'Neill M. Climate change, justice and vulnerability. York, UK: Joseph Rowntree Foundation; 2011 [cited 2018 Mar 21]. Available from: www.jrf.org.uk/sites/default/files/ jrf/migrated/files/climate-change-social-vulnerability-full. pdf

20. Klinsky S, Waskow D, Bevins W, Northrop E, Kutter R, Weatherer L, et al. Building climate equity: creating a new approach from the ground up. Washington DC: World Resource Institute; 2016 [cited 2018 Mar 21]. Available from: www.wri.org/sites/default/files/building-climateequity-072014.pdf

\section{Copyright: (c) (i) (-)}

(C) 2018 Boylan et al. This article is licensed under the Creative Commons Attribution-NonCommercial-ShareAlike 4.0 International Licence, which allows others to redistribute, adapt and share this work non-commercially provided they attribute the work and any adapted version of it is distributed under the same Creative Commons licence terms. See: www.creativecommons.org/licenses/by-nc-sa/4.0/ 